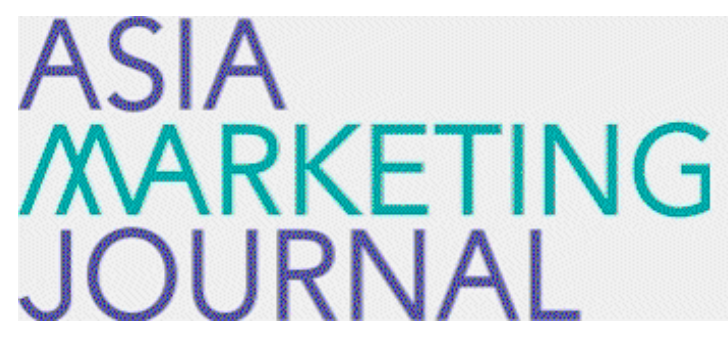

ASIA MARKETING JOURNAL

Volume 14 | Issue 2

Article 1

7-30-2012

\title{
Gifticon, an Innovative New Service Standing at Crossroads
}

Sang Hoon Kim

Hee Jin Kim

Follow this and additional works at: https://amj.kma.re.kr/journal

Part of the Marketing Commons

\section{Recommended Citation}

Kim, Sang Hoon and Kim, Hee Jin (2012) "Gifticon, an Innovative New Service Standing at Crossroads," Asia Marketing Journal: Vol. 14 : Iss. 2 , Article 1.

Available at: https://doi.org/10.53728/2765-6500.1477

This Article is brought to you for free and open access by Asia Marketing Journal. It has been accepted for inclusion in Asia Marketing Journal by an authorized editor of Asia Marketing Journal. 


\title{
Gifticon, an Innovative New Service Standing at Crossroads*
}

\author{
Sang-Hoon Kim** \\ Heejin Kim***
}

Gifticon is an innovative new service of SK Marketing \& Company. Launched in the end of 2006 for the first time in the world. the mobile gift certificate is in the form of a SMS message that bears a bar code to exchange with real products sent to the intended recipient through internet portal, messenger or/and mobile phones. The service started by connecting individuals (B2C business) and was expanded to the new marketing tools of companies (B2B business). While the business took off with soft progress in the initial year of launch. Gifticon business finally gained its momentum in the growth of sales in its second and third year. Yet, the data showed that the growth of user-base was getting stagnant that the number of users remained flat for the past few months. Moreover, competition from latecomers such as Giftishow from KTF and Heartcon from LG Telecom gets fierce. Particularly in B2B sector where Gifticon has made minimal profit, competitors started aggressive promotional activities, taking away shares from Gifticon. Under these circumstances, team is facing tough strategic decisions for its long-term growth: How can they further grow the business? Should they go after more massive targets for broader user-base? Should they pursue B2B business more aggressively? This case study asks students to come up with solutions for these questions by understanding concepts, theories and models for diffusion of innovations and strategies to overcome a chasm.

Key words: diffusion, innovation, high-tech marketing, chasm. B2B marketing

Do you find it hard to deliver a gift yourself? If so, deliver your heart through your mobile phone.

At a coffee or bakery shop, you ve probably seen someone handing his/her mobile phone over to a sales person instead of taking out a wallet. All you have to do for payment is to put a barcode reader to the mobile phone screen. Gifticon service, which enables a user to exchange an economically less burdensome gift without time and space constraints by sending a text

\footnotetext{
* This case was developed with the support from Brain Korea 21.

** Seoul National University Associate Professor(profkim@snu.ac.kr)

${ }^{* * *}$ Korea University Doctoral Student(mene@korea.ac.kr)
} 
message with a gift, is not only cost-effective but also convenient and fun.

May 27. 2009 Donga,com

Already in the middle of September, it was sizzling hot outside with a record high temperature. So was the atmosphere of the meeting room where the SK Marketing \& Company (hereinafter SKM\&C) Gifticon Business Division was having a business review meeting for 2008. It was probably one of the most important events of the year that diagnoses the business performance for the year not only from the perspective of sales and profitability but also from that of users and business partners. The outcome of the meeting would determine business strategies for the following year. Gifticon, launched by SK Telecom in late 2006 and operated now by SKM\&C, is a mobile gift certificate ${ }^{1 \prime}$ via the mobile phone. First of its kind worldwide, it is a service in the form of a SMS message that conceives a bar code to exchange with real products sent to the intended recipient through internet portal, messenger and/or mobile phones. Something like an online gift certificate, this barcode can be exchanged with an actual product in the store. In addition, the user can request his/her acquaintance for a gift through a so-called "urging" function. One can choose the gift from up to almost 300 kinds of menu which can be exchanged with actual products in around
15,000 stores. The service is not limited to the SK Telecom users but the users of LG telecom and KTF, major competitors in domestic telecommunication market. can also enjoy sending and receiving gifticon. As far as business model is concerned, the scope was only to $\mathrm{B} 2 \mathrm{C}$ at the beginning stage but was now expanded to cover $\mathrm{B} 2 \mathrm{~B}$ also for the promotional purposes (Exhibit 1).

The meeting began with a presentation by manager Ki-won Jung. "Gifticon sales soared, up by more than $50 \%$ from the previous year. At the moment, nearly 13,000 purchases are made per day (Exhibit 2). No quantitative consumer analyses are made, yet, awareness particularly among mobile users in their 20s and $30 \mathrm{~s}$ is deemed to have significantly increased. But..."

Even before Mr. Jung continued, team leader Hyuk-jin Ahn was already flashing back the issue that team discussed in numerous strategy meetings. Despite fast growing sales and number of purchases, the number of Gifticon users barely increased. Just a year ago, SKM\&C would have chosen a strategy to gradually broaden the user base. But now, things were different. Strong competitors such as KTF entered this market, albeit belatedly.

A business strategy for next year would be a more important than ever for long-term growth of Gifticon. However, it was not an easy

1) Depending on how you see it. Gifticon can be categorized as a gift certificate, a certificate of custody or a kind of securities. 
decision to make at all. After all, profitability and user-base expansion had to be considered at the same time. Can the company afford to achieve profitability and user base expansion at the same time at this point? Maybe in the short term, the company will soon have to choose one over the other. While team leader Ahn was deep in thoughts for a moment. manager Jung concluded his comments.

\section{The Company}

\subsection{SK Telecom}

SK Telecom (hereinafter SKT) was the first company to introduce Gifticon in the market. SKT is the dominant mobile phone service provider in Korea with over 20 million subscribers and 50 percent market share (Exhibit 3). SKT was also the first to launch a commercial CDMA network in the world and has been continuously developing new businesses such as financial service and satellite DMB service as a pioneer and leader in the Korean mobile service market. Renowned for its creative and innovative corporate culture boosted by aggressive marketing activities, it continuously craves to secure innovative service products as a growth engine to enlarge the market. Gifticon, a combination of creative idea and leading communication technology. was also a fruit from such corporate soils.

SKT's innovative corporate culture is not confined to the new product development. In the area of marketing, the company has identified new consumer needs and fulfilled them by introducing variety of service products. This has led significant changes in market practice which relied mostly on rebate. Segment marketing launched in late 1990s is another example in point. The company segmented the customer base by age and provided differentiated membership service catering to customer characteristics and needs. Age segmentation was implemented by other companies before but what SK provided was thoroughly tailored to the lifestyle of each age group. offering the benefits that went beyond the telecommunication service fee differentiation. The company named the service package for key segments as Ting (for high teens), TTL (for 20s') and Leaders Club (for $30 \mathrm{~s}^{\circ}$ and older) and for example, by showing the membership card of TTL, the members could get the discount for the hot restaurants and theaters for 20s', had the free phone mail or coloring services which were only popular among college students and young adults. They also had the access to TTL zone. a place where they can use internet or meet friends, located around the youngster's hot spots in town. As a result, the company secured strong loyalty from customers of all age groups and has been maintaining rock-solid no.1 status for more than 10 years. 
Key success drivers in operating membership services are as follows. First, the company had an accurate understanding of customer needs through thorough customer analysis. For example, TTL membership for 19 to 24 year olds paid off as it provided discount services at movie theaters, family restaurants, coffee shops, beauty salons, and some other things that these youngsters truly wanted. The second was SKT"s capability to secure and manage such diverse business partners, which is proven to be crucial in the Gifticon business as well.

\subsection{SK Marketing \& Company}

The SK Group envisioned to build a new business model on the basis of marketing capabilities from various subsidiaries such as SKT and SK Energy and established SK Marketing \& Company in early 2008 (Exhibit 4). In a nutshell, SKM\&C, as a specialized marketing entity which integrates and manages marketing activities common to each SK Group subsidiary, represented a total marketing firm with its organic coverage of market research, advertising. customer communication and management.

SKM\&C's business is divided into 5 areas, namely, partnership marketing, communication, commerce, consulting \& research and LBS (Location-Based Service).

Gifticon service was transferred to SKM\&C from SK Telecom in July 2008. Group management viewed that the service would be better suited to SKM\&C's business characteristic and capability in the sense that partnership expansion and management are a core business component for the company. Gifticon's innovative image was also in line with 'Total Value Organizer (TVO)' spirit and SKM\&C's founding spirit to provide unprecedented new values to the company and consumers. Eventually, along with sales and profit growth. SKM\&C was given another mission, i.e. business partner and consumer base expansion.

〈Figure 1〉 Key Businesses of SK M\&C

\begin{tabular}{|l|l|}
\hline \multicolumn{1}{|c|}{ Area } & \multicolumn{1}{c|}{ Contents } \\
\hline Partnership Marketing & $\begin{array}{l}\text { OK Cashbag, membership management, customer differentiation program, Data } \\
\text { Base Marketing(DBM), Customer Relationship Management(CRM) solution }\end{array}$ \\
\hline Communication & $\begin{array}{l}\text { Advertising media planning, media consulting and sales promotion, marketing } \\
\text { campaign agency service }\end{array}$ \\
\hline Commerce & $\begin{array}{l}\text { Gifticon, wedding and childcare, community operation, online shopping mall, } \\
\text { open market place }\end{array}$ \\
\hline Consulting\& Research & Marketing-related consulting, customer research, business marketing training \\
\hline LBS & Telematics, navigation, traffic information, electronic map service \\
\hline
\end{tabular}




\section{Birth of Gifticon}

In March 2006. Aircross, SKT's subsidiary. proposed the idea of sending a mobile barcode to SKT's Business Model Innovation (BMI) Development Division. The basic idea was to deliver product information through a barcode when sending a mobile advertisement. A consumer who received a mobile advertisement message can collect that product if he/she shows a barcode saved in the mobile phone to the relevant store. The idea itself sounded fresh and seemed technically feasible. Nevertheless, as its profit potential did not shine, the mobile barcode delivery proposal had to be archived in the BMI team's 'unexecuted idea inventory' folder.

A few months later, a proposal came up, suggesting the combination of mobile barcode delivery with "emoticon/flashcon ${ }^{21}$ service of Nate On, a popular SKT instant messenger. The idea here was to provide the service that sends emoticon or flashcon together with the barcode of a gift that users choose.

At last, with a KRW 500 million budget for product development and launch, a kickoff meeting for the 'mobile emoticon project' took place. The vision was to explore new business opportunities linking mobile and offline with the expansion of customer service and partner- ship. New service was named 'Gifticon,' a combination of 'gift' and 'emoticon service' provided by SKT.

After 6 months of preparation period, Gifticon first rolled out in the market in Dec. 2006. If the sender of a gift goes through three steps - dialing the mobile phone number of a recipient on Nate On, selecting a product, and completing Internet payment with a credit card or a mobile phone, gift delivery is done! Initial business partners were 7-Eleven and Starbucks. Three kinds of Starbucks coffee including caramel macchiato as well as 20 different products in 13 product categories such as 7 - Eleven steamed bread with red beans and Haagen-Dazs ice cream were available for gift selection. All the Gifticon recipient had to do was to show the Gifticon barcode received through a SMS and collect the gift at a nearby 7- Eleven or Starbuck store.

To increase the awareness of Gifticon, several advertisements were executed on cable TV and newspapers/magazines at the beginning of launching (Exhibit 5). The level of media support was marginal compared to other SKT products. However, much broader exposure oc- $^{-}$ curred on Nate On. SKT messenger service and as a consequence, early users naturally came to regard Gifticon as Nate On's new service. Nate On became Gifticon's core sales channel or point of contact (POC).

2) Emoticon, a combination of emotion and icon, refers to expressing one's feelings and opinions by combining letters, signs and numbers. Flashoon means character illustrations with various expressions. 
Yet, even several months from the launch of the service. Gifticon's sales remained soft, and there was no sign of increase in terms of the number of users. Gifticon certainly contributed to solidify innovative image of Nate On, appearing as a regular guest for various IT exhibitions, and served as a great PR subject in positioning SKT as a leader of cutting edge technology. Ironically, though, actual sales would not grow a bit.

Low awareness and small user base caused a vicious circle barring securing partner companies. Even with the offer of full system investment by SKT, Gifticon was not attractive enough to draw business partners attention. Services like flower delivery were added as the last resort. which has proven to be of little help since no differentiation could be found in such services from Internet-based companies.

\section{Partnership Expansion}

"Gifticon positioned itself as a convergence product which combines mobile. online and offline businesses. $\cdots$ Not only that. the service provides market creating opportunities and distribution cost saving benefits to partner companies that offer products to Gifticon. Gifticon is now being highly rated as a win-win model for both mobile service providers and manufacturers/distributors,"

Hankook Ilbo, 2009
Had the blessing come in disguise? A financial crisis starting from the second half of 2007 offered unexpected new opportunities to the Gifticon business. With shrinking consumption, various companies hit by sales drop came to seek ways for new building blocks and began to consider the partnership with Gifticon favorably. Dominant food chains such as Baskin Robbins, Mr. Pizza, TGI Friday's and Bennigans all came to partner with Gifticon. Additional sales opportunities through Gifticon seemed to appeal to partner companies mainly in two ways. First, Gifticon-based sales generated incremental profit with little cannibalization on the existing sales. Secondly, as customers visiting stores to collect Gifticon often ended up additionally purchasing other products in the store, the potential of further revenue through adjacent sales became available.

An increasing number of partner companies, as previously expected, served as a driving force behind rising sales of Gifticon. Sales soared in 2008. when Dunkin Donuts and Paris Baguette joined partnership. For Gifticon, "partners" were synonymous with products. Particularly at a time when marketing activities were not aggressive, partnership expansion was no doubt a most reliable way to enhance the appeal of Gifticon as a service product. With this in mind, partnership became a core marketing strategy for Gifticon as well as product development (Exhibit 6).

One interesting fact was found in the process 
of partnership expansion. Gifticon came to partner with a number of companies in diverse categories such as bakery shops, coffee shops and family restaurants. Interestingly, sales analysis revealed that no.1 brand in the corresponding category accounted for $70 \sim 90 \%$ market share in the most of categories. It is interpreted that Gifticon's nature as a 'gift' reinforced the principle of "winner takes it all" far more here than in the general market. Of course. offering variety of choices is important. However, what matters more is what specific brand a given product puts on.

If the recipient of Gifticon collects a product at a partner store, the partner company pays $10 \%$ of the purchase price to SKM\&C as a commission. This commission includes various costs incurred to SKM\&C such as spending for SMS and system maintenance. Being higher than the commissions of credit card or gift certificate which is around 3\%, this $10 \% \mathrm{com}^{-}$ mission was one of the main barriers in securing business partners at the beginning. SKM\&C highlighted the fact that specific new products could be promoted. Low cannibalization from the existing business made a good sales talk. too. As a result, Gifticon was getting the perception of a unique service, different from existing gift certificates. As a result, $10 \%$ is now becoming widely accepted as a legitimate Gifticon commission.

\section{Evolution of Sales Channels}

As the user base of Gifticon widened, a huge change was made in sales channels (or POC) as well. Since Gifticon was first released on Nate On. sales through this Internet site accounted for up to $80 \%$ of all direct purchases at the initial stage. However, with the gradual increase in sales, POC was diversified to gifticon. com (Gifticon-specific website) and other 11 wired/wireless POCs portals and messengers (SKT's Cyworld, Buddy Buddy, etc.) and shopping malls (CJ Mall) (Exhibit 7).

Increase in the awareness of Gifticon boosted gifticon.com-based purchase to $40 \%$ of business. Naturally, Nate On-based purchase decreased at about the same percentage. At the moment. SKM\&C is responsible for the Gifticon business and so pays $3 \%$ sales commission to SKT if a Gifticon item is sold through SKT messenger service Nate On. This being the case, sales channel shift from Nate On to gifticon.com made a significant contribution to SKM\&C's improved profit structure.

\section{Expansion of B2B Business}

Rapid partnership expansion coincided with the launch of the Gifticon B2B business. At the time, the Gifticon project team was exploring 
several ideas for sales and user base expansion. One of those was to utilize Gifticon as a promotional item for brands and companies. Gifticon's very first B2B customer was Motorola. When rolling out a new product, the company utilized the service for a promotion event to provide peripheral devices,

B2B service was not only popular but also most effective to offline brands which were conducting aggressive marketing activities in cyberspace. Primarily, it is interpreted that such brands were mainly targeting customers in their 20s and 30s just as Gifticon was. In addition, considering the fact that gift collection is done offline, Gifticon's characteristic that encourages customers to visit an offline store and eventually buy something through an online event came as a major plus point for corporate customers.

Partner companies who offer products to Gifticon became important B2B customers themselves. For example, when launching a new product, they could put that on the Gifticon menu and thus became capable of enhancing product awareness for both Gifticon buyers and recipients, broadening the user-base in a cost-effective way. A case in point was Paris Baguette, which utilized Gifticon at a new item launching event and generated sales increase almost 6 times bigger than that of existing cake items.

Still, a debate continued unabated since the initial stage. What would be the desirable sales split between $\mathrm{B} 2 \mathrm{~B}$ and $\mathrm{B} 2 \mathrm{C}$ ? Which one of these should be the growth engine for the company? Even the working team sharply divided: ones who believed that the growth of B2C would naturally lead to that of $\mathrm{B} 2 \mathrm{~B}$, the others supported that the user base must be broadened first through B2B. There was also a view that B2B service was the optimal business model considering Gifticon's nature as a one-way gift delivery whereas some argued that creation of a B2C market would be difficult once image as a corporate giveaway or coupon became set in stone.

Against this backdrop, business strategies for $\mathrm{B} 2 \mathrm{~B}$ and $\mathrm{B} 2 \mathrm{C}$ experienced change after change. Up until late 2007 when the B2B business started to gain growth momentum, B2C was a focus area while B2B was guided by a rather passive so-called "pull" strategy. However, after mid 2008 when rapid expansion of the B2B market was witnessed, balanced growth of B2C and $\mathrm{B} 2 \mathrm{~B}$ was highlighted. B2B was finally getting more supports than before.

\section{Competition}

When the Gifticon business gained a certain level of awareness and began to generate sales. similar services from competitors emerged in May 2008. They are 'Giftishow' and 'Heartcon. LG Telecom (hereinafter LGT) also announced 
that they would launch a similar service in the second half of 2009. A threat to Gifticon from competitors was particularly prominent in the B2B area. As Gifticon carved out a market and enhanced public awareness of Gifticon service, competitors found it easier to secure business partners than SKT which pioneered the market.

\subsection{Giftishow}

KTF, SKT'S biggest competitor in the domestic mobile communication market, launched 'Giftishow' service with the catchphrase of 'new paradigm in product distribution'. Giftishow made its intention to focus on B2B crystal clear from the very beginning. Upon the launch, they made aggressive marketing investment on and offline marketing events leveraging the partnership with diverse companies. While Giftishow maintained the existing Gifticon characteristic of 'mobile-based gift delivery,' it differentiated itself from Gifticon in two ways. First, as opposed to Gifticon. Giftishow sends a message based on the MMS (Multimedia Messaging Service) method and thus does not charge the recipient any separate data fee (connection fee). Secondly, the sender can add a message of up to 100 letters. Giftshow's business partners include Dunkin Donuts, Burger King, NetMarble(online game portal site), Red Mango(yogurt ice cream). movie theater Cinus, Family Mart(convenience store), GS25(convenience store), Starbucks and Pizza Hut.

\subsection{Heartcon}

'Heartcon' from KTH, the company of well known internet portal site called Paran, is one of major competitors of Gifticon. Heartcon, a barcode-type mobile gift certificate like Gifticon, is being touted as an easy-to-send, convenient corporate marketing tool. Partnership encompasses GS25, Tom N Toms Coffee, Paris Baguette, Burger King, Tire Bank and Pizza Hut. Heartcon recently began to make deeper inroads into the market by holding discount events.

\section{Countermoves from Gifticon}

Despite aggressive B2B-centered activities from the followers, SKM\&C did not take defensive action mainly due to the profitability. In the $\mathrm{B} 2 \mathrm{~B}$ area, the company barely managed to breakeven with the current level of commission fee. If $\mathrm{SKM} \& \mathrm{C}$ matches the level of discount offered by its competitions, B2B would be highly likely to end up a 'losing business.' In addition, it is expected that competitions aggressive marketing activities be unsustainable over the long haul under the assumption that securing a better profit structure than Gifticon would be tough. As a result, the vast majority of B2B customers were opting to use service from competitors with a relatively low commission level. 
In contrast. SKM\&C has gained upper hand in the $\mathrm{B} 2 \mathrm{C}$ area where competing activities are relatively weak. Gifticon's solid market leader image brought high effectiveness of marketing campaigns such as 'day marketing' which utilizes special days for giving specific gifts such as Valentine's Day. For example, up to 70,000 cases of orders were placed on Pepero Day alone which fell on Nov.11. 2008. In Dec. 2008, a whopping KRW 1.9 billion trading volume was made, the highest monthly record ever. The trading volume increased by around $60 \%$ from ordinary times on Valentine's Day (Feb.14) and even by $140 \%$ on the previous day.

Such marketing efforts bore fruit. For example, despite aggressive action taken by competitors, growth of the B2C business almost doubled Gifticon sales for 2009 from the previous year. Monthly sales, which stood at KRW 800 million in early 2008, reached around KRW 2 billion in 2009. However, Giftishow's growth momentum which contributed to rising market share in the B2B area was also a force to be reckoned with. The number of Giftishow users as of April 2009 was 420,000 while the sales stood at KRW 800 million, an impressive four-fold-year-on-year increase in terms of trading amount. The number of monthly users increased too: the number was at around 250,000 in Jan. and Feb., but jumped to 300,000 in March and 420,000 in April.

The Gifticon team judged that B2B service. currently with more than $60 \%$ of total market share, is under exponential growth. A discrepancy surfaced between such market situation and SKM\&C's performance. When it comes to Gifticon, its B2C sales portion, which was around $50 \%$ in late 2008 , rose significantly to $65 \%$ in the first half of 2009 .

\section{Gifticon in a Chasm?}

What was discomforting to team head Hyukjin Ahn was not merely a market competition. Despite steadily growing sales in the B2C area for Gifticon since 2007, the number of users per se began to lose growth momentum. Team head Ahn commented as follows.

"Although it has been taken into consideration, at the moment, no separate member-registration procedures are required to use Gifticon due to risks in high complexities consumers might encounter. Because of that, it is impossible to analyze purchase patterns of individual users. Still, overall sales growth is judged to be mostly from increasing purchase frequency among existing users. This explains why the vast majority of Gifticon users are those in their 20s to 30 s (20- and 30-somethings accounting for $58 \%$ and $25 \%$ of the user base respectively) and why spending per purchase does not increase significantly from the KRW 5,000 range."

If so, why no more increase in the number of users? The team was making several speculations 
on this. First, the size of the gift market through new technology like Gifticon may have reached its limit. In addition, there is a possibility that consumer trial purchase has been made through B2B promotion by competitors and their repeated purchase went back to the respective competition brand. If so, the entry door for new consumers to Gifticon which had been relatively passive about B2B might have narrowed. Lastly. Gifticon might have failed to attract so called 'early majority' with pragmatic nature whereas it appealed to 'early adopters' who prefer innovative products and are quick to adopt them based solely on fresh product ideas and without special communication activities. In other words, Gifticon may have fallen into a chasm.

As soon as manager Ki-won Jung concluded his remarks on user number stagnation and its possible cause, various opinions were voiced. It was a lesson SKT came to learn in the mobile communication business that once the user-base is secured, these users form a positive feedback loop and lay a solid foundation for long-term growth and profitability. Thus, some opined that the company has to actively broaden the user base even despite potential profit loss in early stage in order to create a chain of "the rich-get-richer and the poor-get-poorer." Others maintained that customer needs can be created and developed by corporations in the high tech market, emphasizing on a need for more aggressive communication and marketing activities. Of course, there were those who placed much support on strengthened support for the $\mathrm{B} 2 \mathrm{~B}$ arena. However. in any case, it seemed clear that the prompt expansion of the user base would inevitably result in short-term deterioration in profitability.

If Gifticon embarks on active support towards the B2B business along with full-scale marketing activities, this could trigger cutthroat market competition. Strategy shift from market leader could definitely create ripple effects among competitors. New services soon to be launched by Giftishow and LG Telecom will be directly operated by mobile service provider KTF and LGT respectively, unlike Gifticon which is managed by SKM\&C and thus could face a lighter profitability burden. If that happens, countermoves from Giftishow and others might be stronger than expected.

At the end of the day, the meeting ended without conclusion. However, SKM\&C must choose a future direction by the next strategy meeting scheduled in the following month. $\mathrm{Al}$ ready a few years into the launching of the business, market uncertainty surrounding consumers, competitors, partners and B2B clients were way too big.

〈Recieved April 10. 2012〉

〈Revised May 31. 2012〉

〈Accepted June 04. 2012〉 
Exhibit 1. Gifticon Business Structure and Use

1) Business Structure

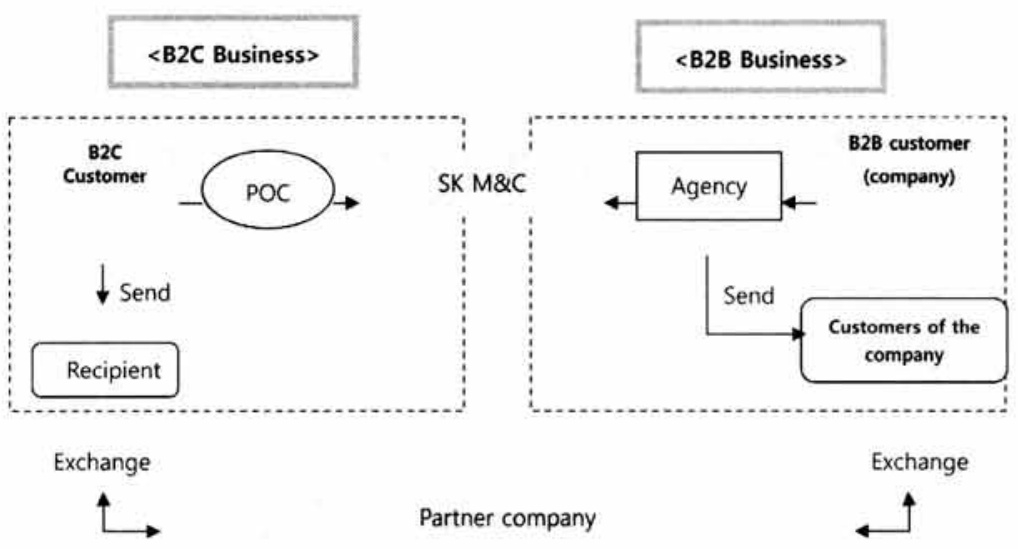

Source: SK Marketing \& Company

2) How to Use Gifticon

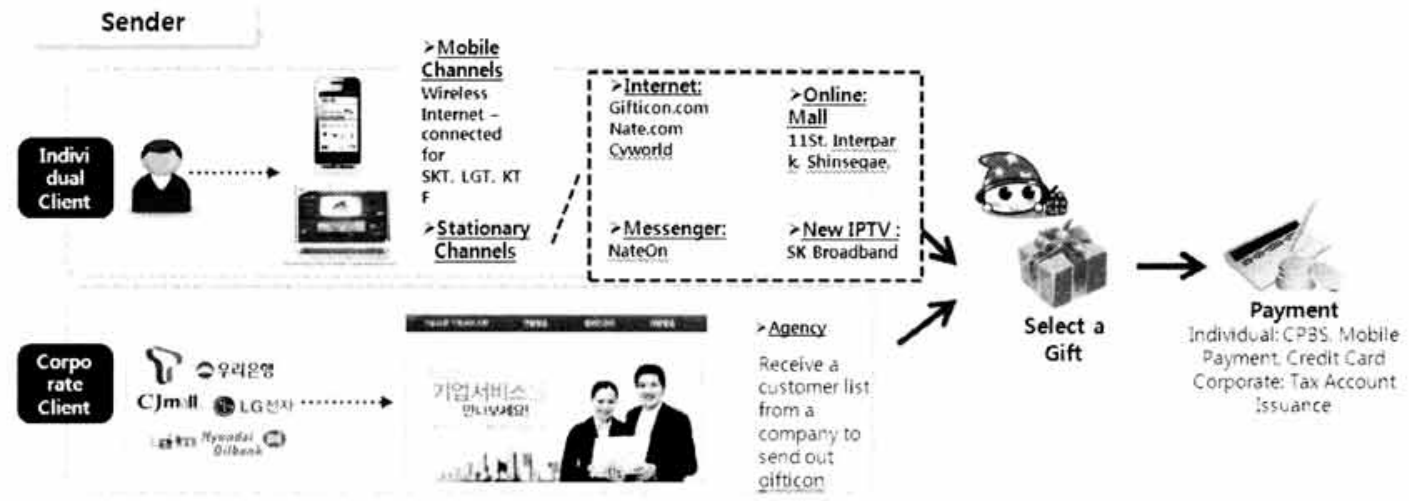

Send

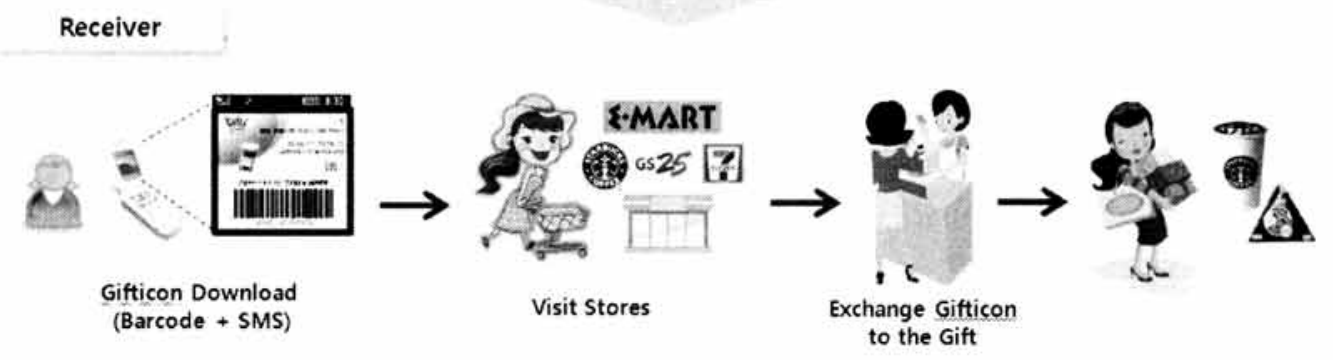

Source: SK Marketing \& Company 


\section{Exhibit 2. Increase in Annual Gifticon Sales and User Number}

\section{2-1) Gifticon Sales}

(Unit: 1 Billion KRW)

\begin{tabular}{|c|c|c|c|}
\hline Year & $\cdot 07$ & 08 & $\begin{array}{c}09 \\
\text { (Est.) }\end{array}$ \\
\hline Sales & 5 & 13 & 18 \\
\hline
\end{tabular}

\section{2-2) No. of Gifticon Users}

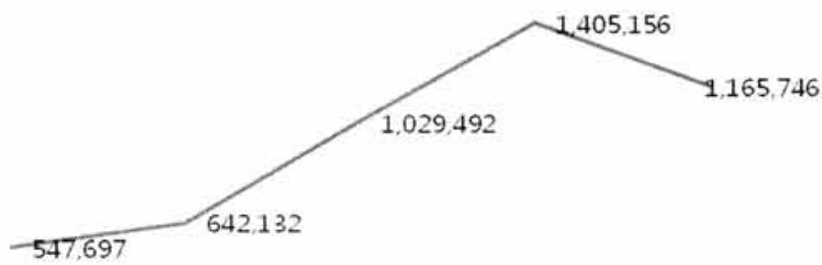

$071^{\text {st }}$ half $\quad 072^{\text {nd }}$ half $\quad 081^{\text {st }}$ half $\quad 082^{\text {nd }}$ half $\quad 091^{\text {st }}$ half

\section{Exhibit 3. SK Telecom History}

198403 Established Korea Mobile Telecommunications Services Co., Ltd.

198807 Launched mobile service

199406 Privatized by the SK Group as the biggest shareholder

199501 No. of mobile and paging service subscribers exceeded 1 million and 4 million respectively.

199601 Launched commercial CDMA mobile service for the first time in the world (Incheon and Bucheon area)

199703 Changed the corporate name to SK Telecom

200012 No. of mobile service subscribers exceeded 10 million.

200110 Launched 'Nate.' a wired and wireless integrated Internet portal service

200301 Launched commercial IMT-2000 service for the first time in the world

200407 Launched 'wired and wireless integrated mobile Cyworld"

200601 Exceeded a record KRW 10 trillion sales

05 Launched commercial HSDPA service for the first time in the world

07 Launched new flagship brand T (T 3G+. T Plan. T World)

12 Launched Gifticon service

200703 Launched commercial 3G service nationwide

200805 SKT Gifticon won 2008 Frost \& Sullivan ICT Award for Most Innovative Application/Product of the Year.

09 Became the first Korean mobile service provider to be selected as Dow Jones Sustainable Index(DJSI)

Source: SKT, http://www.sktelecom,com 


\section{Exhibit 4. SKM\&C History}

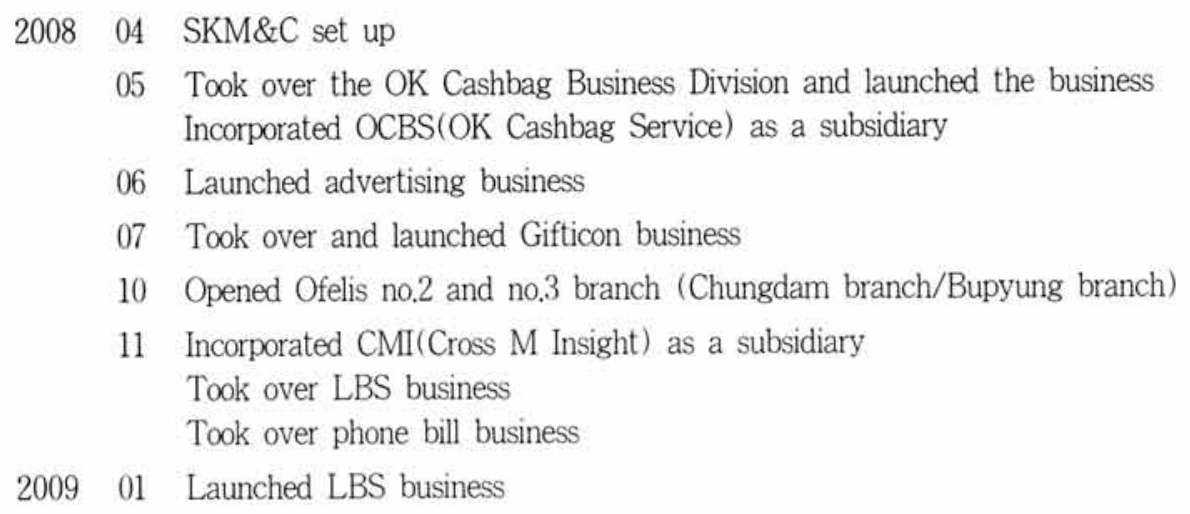

Source: SKM\&C, http://www.skmnc.co.kr 
Exhibit 5. Gifticon Advertising

5-1) Theater/Cable TV Advertising

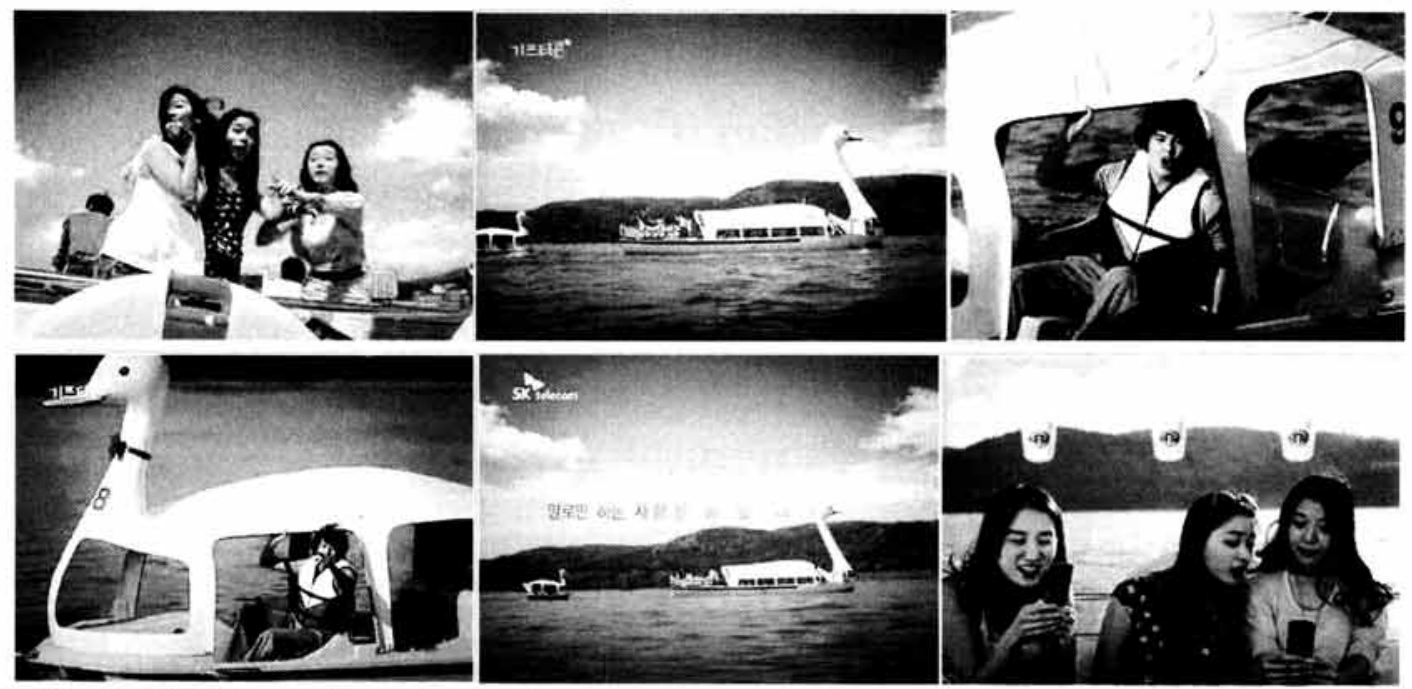

Source: SKM\&C, http://www.skmnc.co.kr

5-2) Magazine/Newspaper Advertising

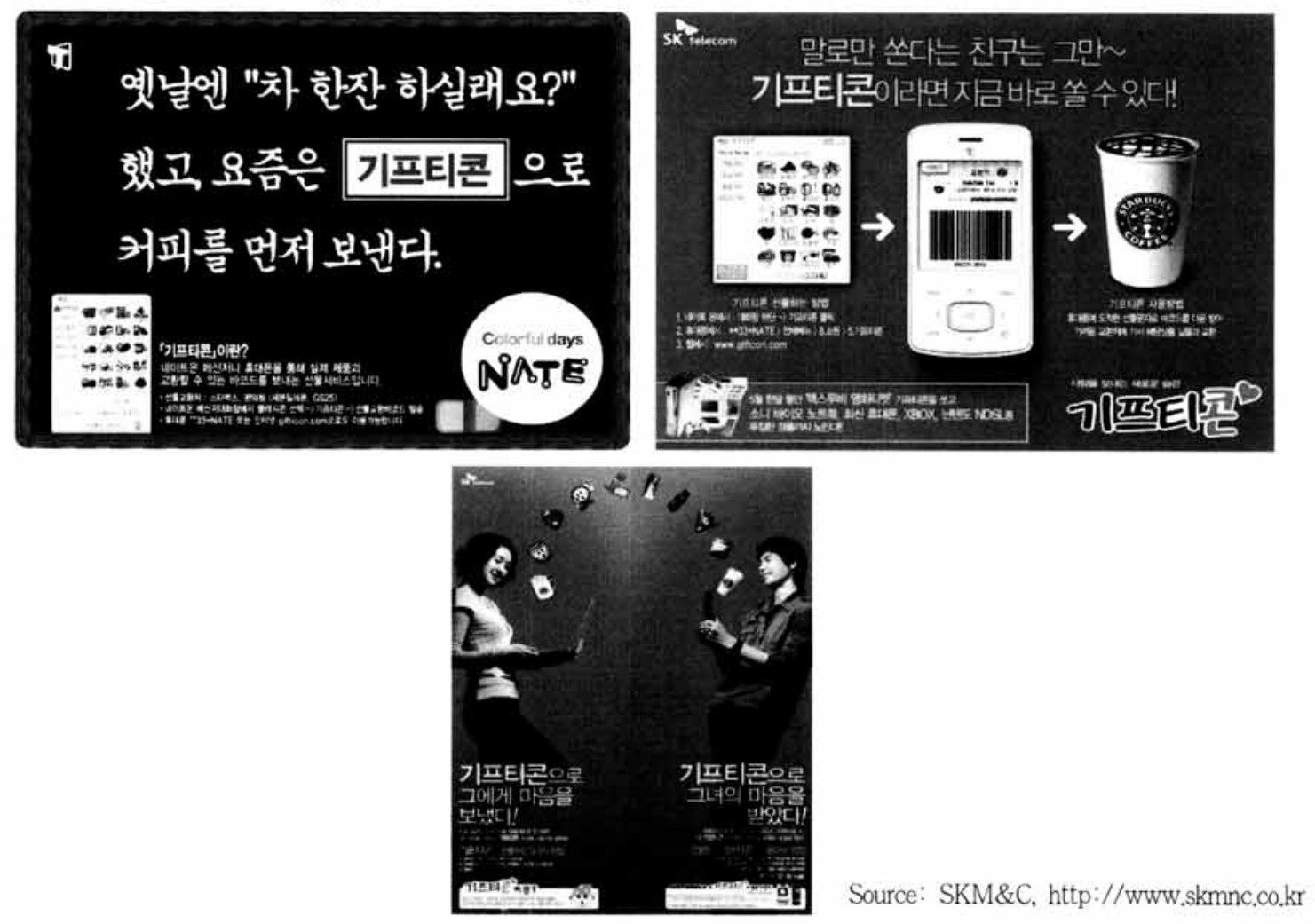




\section{Exhibit 6. Partnerships and Available Gift Items}

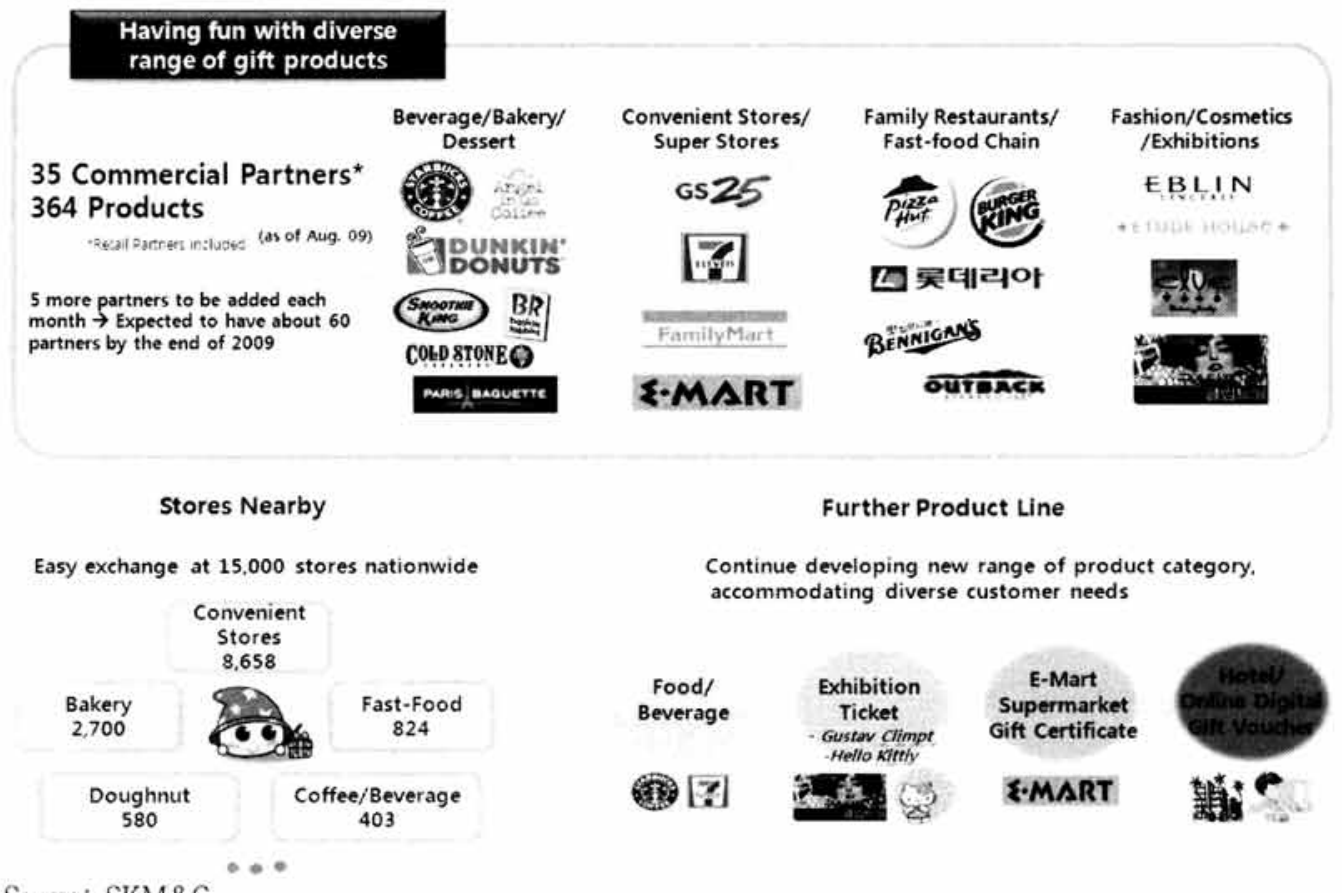

Source: SKM\&C

Exhibit 7. Gifticon POC (Point of Contacts)
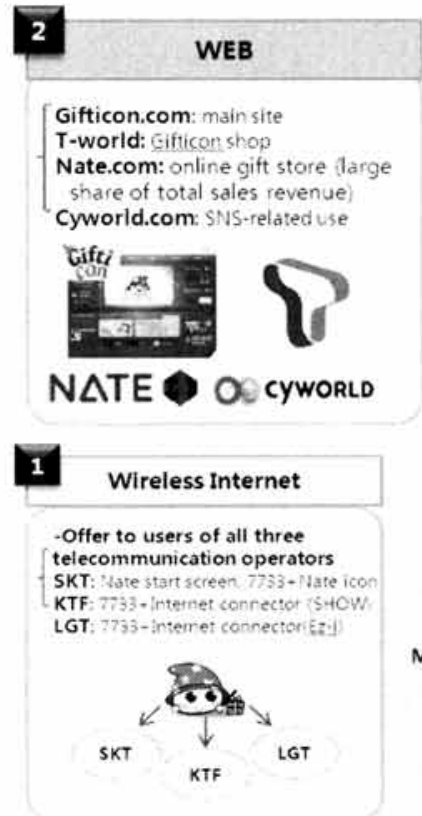

Source: SKM\&C

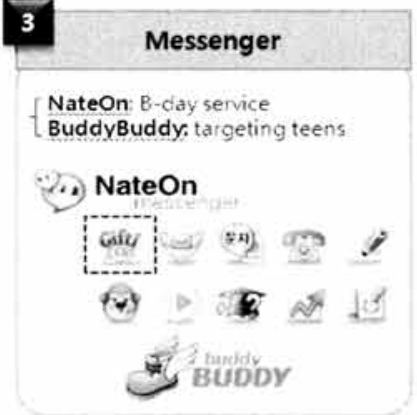

On-Line

Mobile

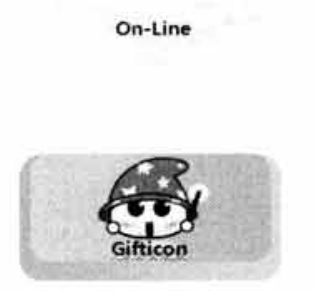

4

Online Shopping Mall

$11 \mathrm{ST}$

interpark

C)mall
SHINSEGAE Mall ST

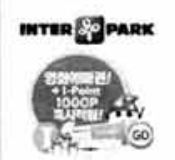

CJm II

* sinsegar MALL.

a?

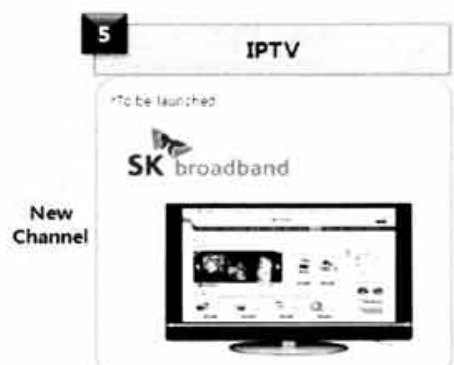




\section{Teaching Note}

\section{Case Summary}

Gifticon is a service that provides a mobile gift certificate from SK Marketing \& Company (hereinafter SKM\&C). Launched by SK Telecom in the end of 2006 for the first time in the world. it is a service in the form of a SMS message that bears a bar code to exchange with real products sent to the intended recipient through internet portal, messenger or/and mobile phones. The service started by connecting individuals (B2C business) and was expanded to the new marketing tools of companies (B2B business).

While the business took off with soft progress in the initial year of launch. Gifticon business finally gained its momentum in the growth of sales in its second and third year. Yet, the data showed that the growth of user-base was getting stagnant that the number of users remained flat for the past few months. Moreover, competition from latecomers such as Giftishow from KTF and Heartcon from LG Telecom gets fierce. Particularly in B2B sector where Gifticon has made minimal profit, competitors started aggressive promotional activities, taking away shares from Gifticon.

Under these circumstances, team is facing tough strategic decisions for its long-term growth: How can they further grow the business? Should they go after more massive targets for broader userbase? Should they pursue B2B business more aggressively? This case study asks students to come up with solutions for these questions by understanding concepts, theories and models for diffusion of innovations and strategies to overcome a chasm.

\section{Study Questions}

1. Discuss the characteristics of the innovative products that influence the rate of diffusion. Evaluate Gifticon against the factors discussed.

2. Considering the product characteristics of Gifticon, select the most appropriate target group for Gifticon business. Explain why.

1) 30 -40 housewives

2) Teenagers with high usage of digital device

3) 20 's working female 
3. Compare Pros and Cons of B2B and B2C business. Propose if Gifticon needs to actively operate its business in B2B segment.

\section{Analysis}

1. Discuss the characteristics of the innovative products that influence the rate of diffusion. Evaluate Gifticon against the factors discussed.

Everett Rogers (1995) identified several attributes of an innovation that influences on consumers adoption behavior based on a synthesis of previous studies examining diffusion of innovations. These include relative advantage, complexity, compatibility, trialiability and observability. While a metaanalysis of innovation characteristics analysis done by Tornatzky and Klein (1982) found that only three innovation characteristics - perceived relative advantage, perceived complexity and perceived compatibility - as being consistently related to adoption behavior, those five characteristics were broadly used to predict the adoption of innovative products. Later on, in his new edition of Diffusion of Innovations, Rogers added perceived risks as additional factors affecting adoption behavior. Often called as "ACCORD" (Advantage - Compatibility - Complexity - Observability - Risk - Divisibility) model, the attributes are broadly used to examine potential success of new products and provide guidelines for initial marketing strategy development.

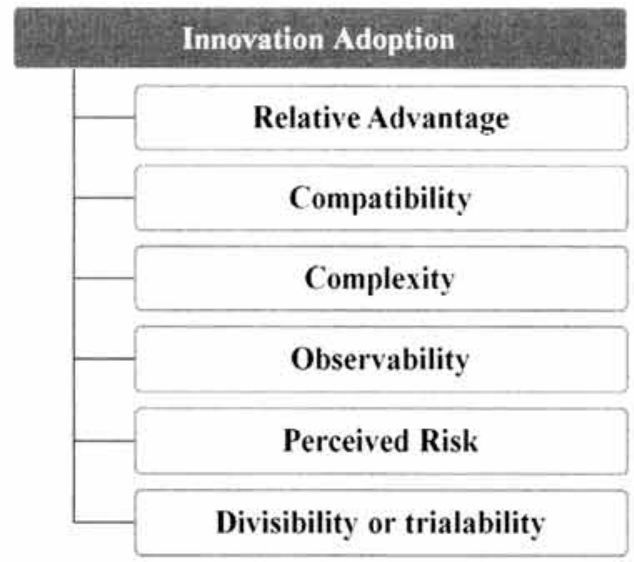

Gifticon - ACCORD analysis

Using ACCORD model, analysis like the following can be conducted. For the case of Gifticon, it 
offers superior convenience in buying and delivering gifts compared with conventional way of gift-giving. On the other hand, givers may perceive the risk of recipients not getting the gifts properly, which potentially hinders the adoption of Gifticon. Most importantly. Gifticon requires changes in gift buying/delivering values and behaviors. Therefore, shrewd marketing strategies that enable consumers behavioral change have to be in place in order to attract broader group of potential users.

Gifticon - ACCORD ANALYSIS

\begin{tabular}{l|l|c}
\hline \multicolumn{1}{c|}{ Attribute } & \multicolumn{1}{c}{ Assessment } & Evaluation \\
\hline $\begin{array}{l}\text { Relative } \\
\text { Advantage }\end{array}$ & $\begin{array}{l}\text { - Easier and more convenient to buy and deliver gifts through internet } \\
\text { and mobile phone } \\
\text { - Can deliver gifts at the exact time when it is most appropriate } \\
\text { - Giving gifts in person is sometimes considered as enjoyable process }\end{array}$ & High \\
\hline Compatibility & - Not compatible with existing gift buying /delivering behavior & Low \\
\hline Complexity & - Easy to use & High \\
\hline Observability & - Limited observability & Low \\
\hline Risk & - Gift recipients may not be aware of whether they received Gifticon. & High \\
\hline Divisibility & - Lift recipients may not be able to use it or forget to redeem it. & Low \\
\hline
\end{tabular}

2. Considering the product characteristics of Gifticon, which is the most appropriate target group to save Gifticon business from Chasm (the stagnation coming after the initial market)? Select the most appropriate consumer group among followings and explain why..

1) 30-40 housewives

2) Teenagers with high usage of digital device

3) $20^{\circ}$ s working female

For this question, the concept of "chasm" and its coping strategies can be discussed. On the basis of technology adoption lifecycle model by Everette Rogers, Geoffrey Moore (1991) argued that there is a gap between the early adopters of the product and the early majority, caused by the different expectations towards the products. According to Moore, different sets of techniques are required to successfully cross the chasm in choosing targeting. positioning and building marketing strategies.

- Chasm Overcoming Strategy: "Bowling Alley"

Like in bowling. where one or two pins are targeted to trigger a chain reaction to get a strike, target group segments should be tackled to target the most promising target. The only way to overcome a chasm is to concentrate available resources on one niche market. 


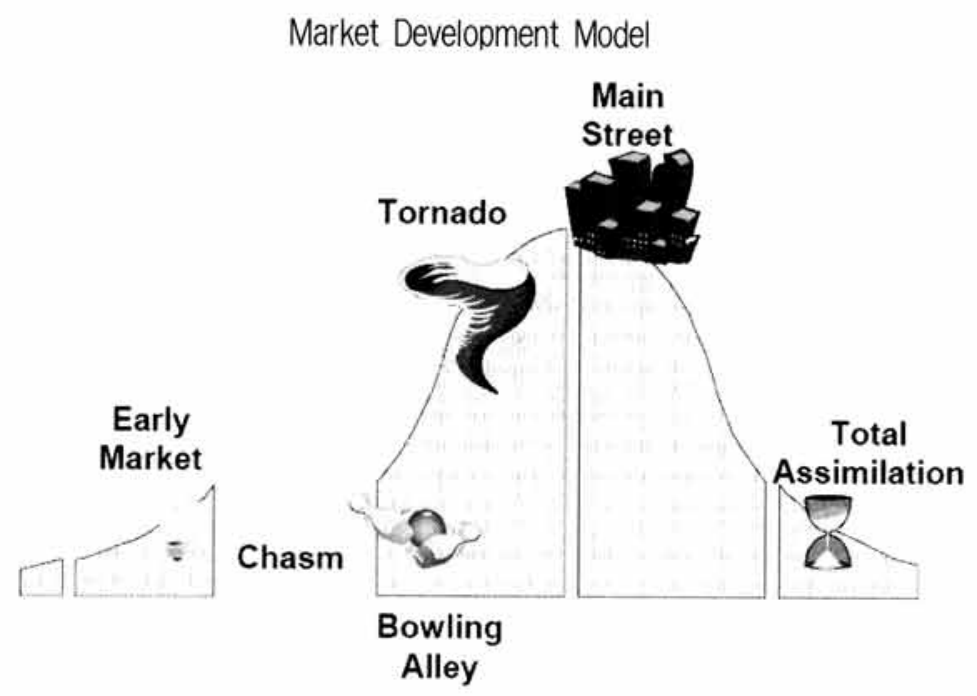

To cross the chasm, the company needs to focus on one niche market (Moore, 1991). Like how bowling pin triggers a chain reaction to get a strike, once the company owns that niche market. satisfied users are likely to spread positive word-of-mouth to the other groups of people and enable the innovation to attack mainstream. Then, how should we select the first niche market? The first criterion is "a right to win", whether the innovation could appeal to consumers considering its relative advantage and consumers' needs. Secondly, the market should be able to serve as "leverage" to successfully connect to mainstream group with ripple.

Taking above considerations into account, scenario analysis is one of the most frequently used method in deciding targets for innovative products. Scenario analysis segments markets in terms of three levels, i.e., product, customer and application. Assign a typical representative of target group and imagine their daily life to evaluate the value of the products and its applications. Using the scenario method, we could evaluate three target groups suggested in the question as follows.

Based on the scenario analysis, teenagers and $20^{\circ}$ s working female turned out to be the groups with higher potential. The appeal of Gifticon and the various products offered to select is higher than other consumer group. For teenagers who have relatively low buying power and whose one-time cash outlay is small, short-term profitability could be compromised. Therefore, companies are likely to prioritize $20^{\circ}$ s working female over teenagers. However, given their tighter social network, high needs of socialization, high frequency of mobile message utilization and influence to parents, this group holds the highest potential to expand the user basis quickly. Moreover, these people would grow to the consumers with buying power in a year or two. Providing a complete solution with affordable prices is essential. 


\begin{tabular}{|c|c|c|c|c|c|c|}
\hline & \multirow[t]{2}{*}{ Characteristics } & \multicolumn{5}{|c|}{ Application of the products } \\
\hline & & $\begin{array}{c}\text { Urging } \\
\text { Function }\end{array}$ & $\begin{array}{l}\text { Coffee, } \\
\text { Cakes and } \\
\text { Bakery }\end{array}$ & $\begin{array}{l}\text { Grocery } \\
\text { Coupons }\end{array}$ & $\begin{array}{l}\text { Digital } \\
\text { Contents } \\
\text { (Music } \\
\text { file, etc.) }\end{array}$ & $\begin{array}{l}\text { Tickets for } \\
\text { movie, art } \\
\text { exhibition } \\
\text { or play }\end{array}$ \\
\hline $\begin{array}{l}30-40 s^{\prime} \\
\text { house- } \\
\text { wives }\end{array}$ & $\begin{array}{l}\text { - Relatively low openness } \\
\text { to innovation adoption } \\
\text { - Gifts for family } \\
\text { members or those in } \\
\text { formal relationship }\end{array}$ & 2 & 3 & 3 & 2 & 3 \\
\hline $\begin{array}{l}\text { Teenager } \\
\text { (Student) }\end{array}$ & $\begin{array}{l}\text { - Open to new } \\
\text { technologies } \\
\text { - Highest needs for } \\
\text { socialization } \\
\text { - Low level of spending } \\
\text { - Active social network }\end{array}$ & 5 & 3 & 1 & 4 & 3 \\
\hline $\begin{array}{l}20 \text { 's } \\
\text { working } \\
\text { female }\end{array}$ & $\begin{array}{l}\text { - High spending } \\
\text { - Open to try new things } \\
\text { - Active social network }\end{array}$ & 4 & 4 & 3 & 3 & 4 \\
\hline
\end{tabular}

(Scale - 1: not usable / 2:Usable but no obvious benefits / 3:nice to have / 4 : should have / 5 :must have)

3. Compare Pros and Cons of B2B and B2C business. Propose if Gifticon needs to actively operate its business in B2B segment.

B2B and B2C business of Gifticon service can be compared as below

\begin{tabular}{c|l|c}
\hline & \multicolumn{1}{|c|}{ B2C } & \multicolumn{1}{c}{ B2B } \\
\hline \multirow{5}{*}{ Descriptions } & $\begin{array}{l}\text { A service where an individual customer, from the } \\
\text { Gifticon website, online nate, mobile nate and } \\
\text { nateon messenger conversation window, will choose } \\
\text { a product to give to his/her friend, or ask a friend } \\
\text { to offer a gift }\end{array}$ & $\begin{array}{l}\text { A service where a corporate customer will choose a } \\
\text { product from the Gifticon website to present to its } \\
\text { customers in promotional, publicity or/and }\end{array}$ \\
compensation purposes
\end{tabular}


At the current situation of the Gifticon business, the most important issue regards profitability and identity.

- Profitability issue: As the competitors concentrate on the B2B field, the competition has intensified to a certain level. In this B2B business, while the level of commission is barely maintaining a level above the break-even point, a cutthroat competition will only worsen the profitability and negatively affect the business.

- Identity issue: In a normal growth model, B2C business growth will naturally trigger B2B business growth. For B2C business to grow properly, it is essential for customers to identify the characteristics of the service ( $=$ a service to present a product exchange coupon). On the other hand, if B2B growth happens ahead of B2C growth, there is a risk where customers might recognize this service as a plain giveaway or a free coupon.

While the B2B business margin is low, in the long term perspective, and in the consideration of the market potential, it will be a big profit gainer for SK M\&C with no doubt. And more, consumer penetration through $\mathrm{B} 2 \mathrm{~B}$ might prove to be more effective in widening the user base. On the contrary, a pressing jump to concentrate on B2B without a proper foundation of a $\mathrm{B} 2 \mathrm{C}$ market might bear a high risk. SKM\&C will have to take these considerations into account and to develop both B2C and B2B, in a synthetic business model. At this stage, it is more advisable to first concentrate on $\mathrm{B} 2 \mathrm{C}$ business to solidify the base and maintain a passive countermeasure to competitors which focus on B2B strategies. When the level of growth becomes satisfactory in the B2C business, the growth will naturally be shifted to the growth of the B2B business.

\section{References}

Moore, Geoffrey (1991), Crossing the Chasm, Harper Business, New York: NY. Rogers, Everett (1995), Diffusion of Innovations, $4^{\text {th }}$ edition, Free Press, New York: NY.

Tornatzky, L. G.. and R. J. Klein (1982), "Innovation Characteristics and Innovation AdoptionImplementation: a Meta-Analysis of Findings," IEEE Transactions of Engineering Management: EM-29, 28-45. 